\title{
OVERVIEW OF STANDARDS TOWARDS ROAD ASSET INFORMATION EXCHANGE
}

\author{
Michael G. Niestroj ${ }^{1, *}$, David A. McMeekin ${ }^{2}$, Petra Helmholz ${ }^{2}$ \\ School of Earth and Planetary Sciences, Discipline of Spatial Sciences, Curtin University, Perth, Australia - \\ ${ }^{1}$ Michael.Niestroj@postgrad.curtin.edu.au \\ 2 (D.McMeekin, Petra.Helmholz)@ curtin.edu.au
}

Commission IV, WG IV/7

KEY WORDS: Austroads, Asset Management, Data Standards, COBie, IFC, Information Exchange, Road Network

\begin{abstract}
:
Governmental agencies, companies and other organisations benefit from sharing data effectively using a harmonised data specification. In asset management, data standards exist from the construction phase through to the operation of the building. A gap exists within transport agencies in Australia and New Zealand for the road asset information exchange. The expectation is that by transferring road asset data from one system to another using a commonly accepted data standard, annual cost savings are predicted to be achieved within these countries of between $\$ 65$ and $\$ 130$ million. Current developments are investigating standardising road asset data. This research provides a critical review of data standards for vertical and horizontal infrastructure, namely buildings and roads, and reviews current approaches that deal with the challenge of information exchange for the road network.
\end{abstract}

\section{INTRODUCTION}

A business case developed by Austroads demonstrated that significant benefits and cost savings can be obtained by utilising a harmonised road asset data standard (Austroads, 2016a). The estimated cost savings are $\$ 65$ to $\$ 130$ million per annum by using a common data standard that allows road asset data to be transferred between different software systems (Austroads, 2015). A road construction project consists of six stages (acquisition, construction, design, disposal, operations and planning), as shown in Figure 1. The stages can be categorised into two groups, asset management and asset development. A requirement for the information exchange within these different stages is that infrastructure objects need to use a unified language. This is currently not given and therefore a gap exists for the information exchange of roads asset data (East et al., 2016b). For instance, in the asset development, road asset data needs to be handed from design to construction. While within road asset management, information needs to be exchanged in a continuing process between disposal, planning, acquisition and operations (Austroads, 2016b).

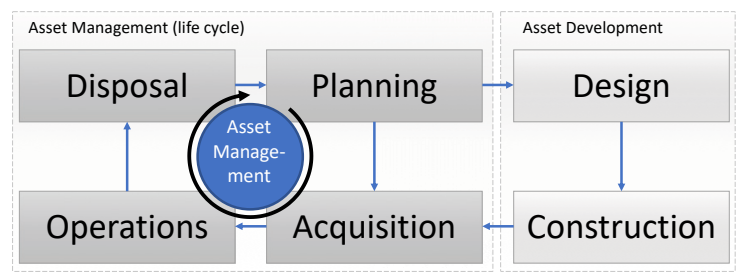

Figure 1. The asset lifecycles stages are categorised into asset management (disposal, planning, acquisition and operations) and asset development (design and construction) (Austroads, 2016b).

Currently, an issue of transferring road asset data between stakeholders within the above-mentioned stages exist because many national, international and specific standards are available (e.g.

\footnotetext{
${ }^{*}$ Corresponding author
}

buildingSMART IFC; COINS; INSPIRE Transport Network; ISO TC211; Inframodel (Finnish); NASA/TQ QUDT; SOSI (Norwegian); OGC InfraGML; OKSTRA (German); RWS-OTL (Dutch); W3C SKOS and PROV-O). However, the use of one data specification is not standardised (Pecharda, 2017). Information and knowledge sharing are therefore very difficult to process as no available system is capable of enabling the communication between these mentioned data standards. The same challenges apply for the transition of legacy data that needs to be employed within an updated software environment.

Many working groups are investigating the challenge of road asset information exchange (e.g. Pecharda, 2017; Hausknecht, 2018; V-Con, 2016; Consultants, 2018; Haider et al., 2012). Some of these activities are finalised (e.g. V-Con, 2016; Hausknecht, 2018), while others are not completed yet (e.g. Pecharda, 2017; Consultants, 2018; Haider et al., 2012). However, the outcome of these projects is often an overall description of a standard specification, concept or recommendation rather than an implementation with working examples based on real-world data sets. To the best of the authors' knowledge, there are only a few implemented road network information exchange approaches available that process real road data, such as Malmkvist et al. (2017) and Schaller et al. (2017).

Malmkvist et al. (2017) employed InfraGML and IFC Alignment for the information exchange of road asset data between the design and operation phases of a road project. Whereby, Schaller et al. (2017) demonstrated the industrial application of road asset information exchange between Building Information Modelling (BIM) and Geographic Information Systems (GIS). Both approaches are summarised more in detail later in this paper.

This paper provides an overview of available data standards and software products for road asset information exchange. Each data standard will be analysed for the use within transport agencies in Australia and New Zealand. Finally, implemented road network information exchange approaches are summarised to understand current developments. 
The structure of this paper is organised as follows. First, an overview of asset management standards with a specific focus on those for vertical and horizontal infrastructure will be provided. The location and linear referencing for road assets will be then explained. Finally, standards and software systems related to road asset information exchange are presented and further evaluated with available industrial implementations are described.

\section{ASSET MANAGEMENT}

Asset management is about procedures and actions that need to be executed for the maintenance of physical assets to maximise its value to the organisation $(\mathrm{B} \emptyset, 2015)$. The definition of asset management, policies about requirements, and guidance of an asset management system can be found in the ISO 55000-50002 asset management standards suite.

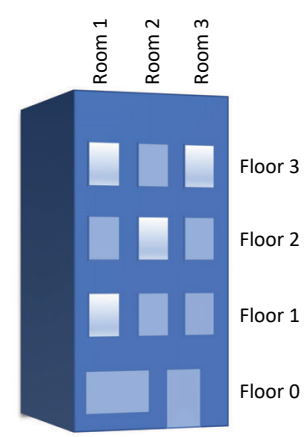

Vertical Infrastructure

Object oriented location referencing (e.g. building, floor and room)

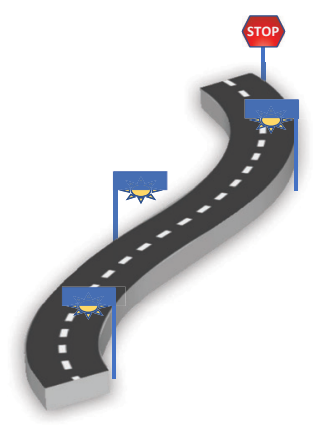

Horizontal Infrastructure Mixed location referencing: - Polylines (line, clothoid and circular arc elements) - Points

- Distance along lines
Figure 2. A simple example to visualise the differences addressing the location aspect of vertical and horizontal infrastructure (Kenley and Seppänen, 2009; McCrae and Singh, 2009).

Asset management can be sub-divided into vertical and horizontal infrastructure considering the location aspect. For instance, the vertical infrastructure uses a simple hierarchical location breakdown (e.g. building, floor, room, etc.), while the horizontal infrastructure requires a combination of polylines, points and distance along lines to describe roads and their inventory (e.g. lightning and signs) as shown in Figure 2.

\subsection{Vertical Infrastructure}

Asset management for vertical infrastructure (also known as building asset management) is usually performed using one of two methods - Industry Foundation Classes (IFC) and Construction to Operations Building information exchange (COBie).

The IFCs by buildingSMART are accepted as ISO 16739 standard and used to exchange and share data among participants of a building construction or facility management project (BuildingSMART, 2017). With COBie, a subset of IFC, it is possible to capture operations, maintenance, and asset management information from building projects (East et al., 2016a).

Vertical infrastructure asset management methods are not suitable for the use within horizontal infrastructure because of the previously mentioned location breakdown characteristics.

\subsection{Horizontal Infrastructure}

The IFC Alignment is an IFC extension for horizontal infrastructure and is integrated into IFC $4 \times 1$ (BuildingSMART, 2017). It is the fundamental base for further projects, such as IFC Bridge, IFC Rail and IFC Road which are part of the next IFC major release (Liebich, 2015). The two most significant features of the IFC Alignment are (Kenley and Harfield, 2015):

1. Extended IFC specification that includes data from the Open Geospatial Consortium (OGC), designed to support global geographic coordinates and levels.

2. Specific representation of geometric data to ensure that the alignment data is interoperable between projects.

Location is an important aspect to describe an asset's position, as there are local and global coordinate systems employed in different areas in the road asset's life cycle. For instance, local coordinates (e.g. linear referencing) are used in road design, whereby, global coordinates are utilised in the construction and operation phases.

A location can be referenced by different methods. Some of the well known referencing methods are for instance postal address and coordinate system (e.g. WGS84). According to NCHRP (1974), the location reference method is a definition of a specific location relative to a known point.
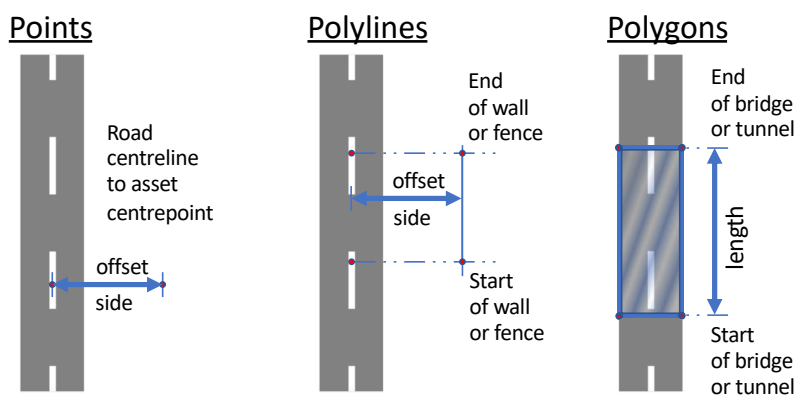

Figure 3. The principle of road asset location referencing using points, polylines, and polygons (Consultants, 2018).

In Australia and New Zealand three item location referencing approaches are utilised within the national transport agencies to describe the location of road inventories (e.g. bridges, fences, lighting and parking): points, polylines, and polygons (Consultants, 2018). An example of each of these methods is simplified and illustrated in Figure 3. The left image shows the point location referencing method with road asset positioned with an offset relative to the centreline of the road. The middle image shows the polylines approach with the location reference relative to the start/end point of a wall or a fence, whereby the asset length is defined by the distance between these two points. Both images share the information on which roadside the asset is localised. The right image indicates the polygon location reference approach for a bridge or tunnel by defining the start/end points of the asset. The asset length is again represented by the distance between the asset start and end points.

The most common referencing approach used by transport agencies around the globe for the planning, operation and maintenance phases is called linear referencing. Thereby, the location of an asset is measured along a linear element (Scarponcini, 2002). 


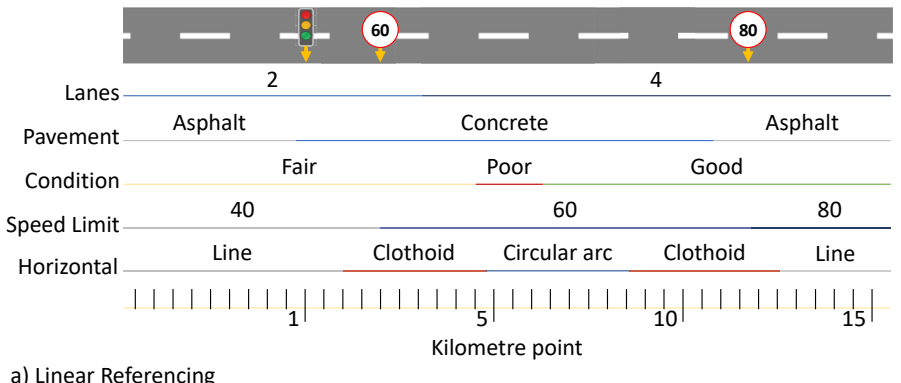

a) Linear Referencing

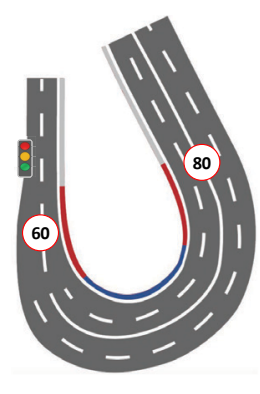

b) Horizontal Alignment

Figure 4. A linear referencing approach of a sample road is indicated in a) (Maryland, 2014), and b) shows the horizontal alignment illustration of the same road sample (Malmkvist et al., 2017).

An example oriented to the implementation from the transport agency of the U.S. state of Maryland with the difference of using kilometre points instead of mile points is indicated in Figure 4a. The kilometre/mile points are installed by transport authorities on highways, freeways and other roads as location reference points. The location of an asset is relative to the position of a reference point (Scarponcini, 2002). The linear referencing system of this example shows speed limit, pavement type, pavement condition, number of lanes, inventory and horizontal shape. Reference points are installed every five kilometres indicated as bold lines on the scale. The road network information at kilometre point 1 indicates, for instance, a speed limit of $40 \mathrm{~km} / \mathrm{h}$, with a fair concrete pavement condition, two lanes and a traffic light installed at this location. Two more inventories are also installed on the road. A $60 \mathrm{~km} / \mathrm{h}$ speed limit sign is located two kilometres away from kilometre point 1 , and an $80 \mathrm{~km} / \mathrm{h}$ speed limit sign is positioned about three and a half kilometres after kilometre point 10. As one can understand, the description of road assets using the linear referencing method is quite simple. A sophisticated road asset data standard should be able to process linear referencing methods as it is a standard approach within the road network industry.

Figure $4 \mathrm{~b}$ shows the same road part as a horizontal alignment with respect to the road shape represented by a line, clothoid and circular arc. This visualisation method is good for design but not suited for asset management as it is time-consuming to generate a graphical representation of the road structure. In comparison, the use of a linear referencing approach is fast and efficient. For example, the number of road lanes changed from two to four, asset managers using the linear referencing approach have only to adjust the number of lanes in their asset management programme. Whereby, the road designer has to spend much more time adjusting the number of lanes in their software environment. A good data specification should enable the displaying and processing of a road (with shape and inventory) automatically, depending on the available information extracted from a data set. This requires a data specification that can handle road asset information in all stages of road development: design, construction and operation.

\section{OVERVIEW OF STANDARDS}

This section gives an overview of available developments related to the management of road asset data. This information is subdivided into standards that enable road asset information exchange and software solutions for the industrial road network asset management.

\subsection{Data Standards}

3.1.1 BuildingSMART IFC As already described, buildingSMART IFC's are within the industry integrated data model standards. There are existing Model View Definitions (MVD) that are IFC subsets (e.g. BIMSie, BPie and COBie) to simplify the use of IFC for specific tasks by utilising spreadsheet files. The IFC MVD projects can be contributed by joining the buildingSMART alliance ${ }^{1}$. An MVD requirement is to employ the label "information exchange" (McPhee, 2016). A working title of an MVD project for road network asset management is CONie or Construction to Operations Network information exchange (East et al., 2016a) that will fill the gap of road asset data information exchange from existing construction data to the operational asset management.

The IFC's are sophisticated developments and support linear referencing with IFC 4x1 and IFC Alignment (Muhic, 2016). The application of IFC is mainly contributed to BIM. In Australia and New Zealand, the IFC's could be used for road asset information exchange, however, this technique is rather complicated, as it requires time to implement. An MVD for the road network as mentioned would enable a simple implementation of IFC in transport authorities. Thereby, the usability must be as comfortable as possible so that transport agencies are willing to adopt an IFC road asset data exchange specification for their needs.

3.1.2 OGC LandInfra/InfraGML The Open Geospatial Consortium (OGC) $)^{2}$ is an association of about 518 members from companies, government agencies and universities that provide Open Standards about location. Their information exchange standard for the road network is called OGC LandInfra/InfraGML.

The Land and Infrastructure Conceptual Model covers land and civil engineering infrastructure facilities, which include the subjects projects, alignment, road, railway, survey, land features, land division, and "wet" infrastructure (storm drainage, wastewater, and water distribution systems).

The InfraGML standard is sub-divided into eight parts. They are: InfraGML Core, LandFeatures, Facilities and Projects, Alignments, Roads, Railways, Survey, and LandDivision, respectively labelled as parts zero to seven. The fourth part supports roads and road cross-sections which are further included as requirements classes in LandInfra. For road support, an application must also support InfraGML Core, Facility, and LandFeature requirements and may support the alignment requirements class. For the road

\footnotetext{
${ }^{1}$ National Institute of Building Sciences: http://www.nibs.org

${ }^{2}$ Open Geospatial Consortium: http://www.opengeospatial.org
} 
cross-section support, an application must further support the InfraGML Road class (OGC, 2017).

The OGC InfraGML data specification is suited to be used within transport agencies in Australia and New Zealand. The InfraGML language is simpler to implement compared to the previous IFC standard as it uses a readable XML file format. The GML data standards are often used in GIS developments. Therefore, an InfraGML based information exchange within transport agencies could support road project's during the development, as GIS can be employed for environmental analyses (e.g. flooding, land movement and road usage).

3.1.3 INSPIRE The Infrastructure for Spatial Information in Europe (INSPIRE) ${ }^{3}$ directive focuses on the development of a spatial data infrastructure for the European Union. This spatial data infrastructure facilitates data sharing between public sector organisations, enable public access to spatial information and support in policy-making across Europe's boundaries. It is established and operated by the member states of the European Union. This directive will contribute 34 spatial data themes for environmental applications (e.g. addresses, coordinate reference systems, elevation and transport networks).

The INSPIRE transport networks theme will enable data exchange between road, rail, air and water transport networks, as well as their related infrastructure. Their road transport networks application schema uses a linear network with a link and node structure to represent the road network (INSPIRE, 2014).

Currently (as of July 2018), only Slovenia has implemented the INSPIRE transport networks theme as part of the Slovenian Geoportal. As only one stakeholder has implemented INSPIRE, it cannot be said how effective the data exchange between the European countries works. However, according to INSPIRE's roadmap, the INSPIRE specification will be employed by all stakeholders by December 2021. If the transport network theme will be successful established in Europe, then an INSPIRE oriented approach can positively influence the road asset data exchange development of other transport authorities, such as transport agencies in Australia and New Zealand.

3.1.4 OpenTNF A data specification for the road network information exchange is available with the Open Transport Network Format (OpenTNF). It specifies a set of classes that may be implemented as data tables in a relational database. The aim of OpenTNF is to specify an Open Standard for the exchange of large transport network data. It conforms to INSPIRE's data specification on transport networks, and data sets to and from national road databases. An OpenTNF data set may contain different data types, such as (OpenTNF, 2017):

- The transport network with the description of linear referencing, geometric, topological and temporal aspects.

- Transport properties (attributes and features) related to the transport network and/or geography using linear referencing mechanism.

- A catalogue to define the various transport properties types.

- Metadata definition according to a standard specification such as ISO 19139 (geographic information - metadata).

- Information related to data set updates.

\footnotetext{
${ }^{3}$ INSPIRE: http://inspire.ec.europa.eu
}

The OpenTNF standard is another candidate for the road asset information exchange in Australia and New Zealand. It is based on the OGC GeoPackage development. According to Triona (2018) OpenTNF is chosen by the Swedish Transport Administration as their data standard. Although the documentation is well explained, there are currently no data examples available and, therefore, an implementation within Australia's transport agencies requires an additional proof of concept.

3.1.5 Austroads Data Standard For Australia and New Zealand, the Austroads data standard is a long-term solution and further a huge benefit to adopt a unified road asset data format. This data standard offers further an opportunity to overcome issues in the data harmonisation between the different states (e.g. New South Wales, South Australia and Victoria).

The Austroads data standard is currently in its second version (as of June 2018). However, there are elements identified not covered. For example, Gelder (2018) criticise that the data standard has no hierarchical structure and that some data specifications are missing (e.g. drainage, pathways properties, crossings and lamps). Another disadvantage is that there are currently no example road projects available. By means of a sophisticated standard specification, examples must be available which can further be loaded into an external software application to visualise and validate data sets. This opportunity is not given within the Austroads data standard, however, it must be included to allow an effective use with the opportunity to visualise entered road assets.

\subsection{Software Systems}

3.2.1 Trimble Novapoint The Trimble Novapoint ${ }^{4}$ software is integrated into Trimble Quadri, which is a BIM solution for infrastructure projects. Novapoint allows civil engineers to design effective all aspects of roads, railways, bridges, water and sewer. The Novapoint Road software is an industrial software tool for professional road design and its templates are based on local standards. The software covers the advanced design of alignments, road models and intersections. Projects can be analysed for a range of different aspects such as volume, sight distance and vehicle tracking.

Quadri is used by all Novapoint modules and is a platform to store large amounts of geographically oriented data. To store files on a file-based server Quadri uses a database system developed by ViaNova Systems, while if configured as a server solution, the central database is Oracle. The Quadri system is able to manage networks, vector and raster data. It uses its own data management system that allows high-speed calculations, feature type, network and area search.

3.2.2 Triona TNE The Transport Network Engine (TNE) $)^{5}$ is a software platform to organise information about transport networks and network-related features (e.g. infrastructure assets, state, characteristics, regulations, and usage). The TNE software enables management of road, rail and waterway network data. It provides further opportunity to guide activities for the automotive and insurance areas related to road, rail and shipping.

The TNE product allows data collecting and editing in different contexts and applications within an organisation. It also supports data sharing and is therefore applicable for the collaborative information exchange between organisations; other benefits are security, data integrity and quality.

\footnotetext{
${ }^{4}$ Trimble Novapoint: http://www.novapoint.com

${ }^{5}$ Triona TNE: http://tne.triona.se
} 
The TNE is built on Open Standards from OGC, ISO/TC 211, and INSPIRE. The TNE model conforms to OpenTNF and RailTopoModel ${ }^{6}$, and is designed to manage:

- The transport network topology with 3D-geometry, temporal validity, and linear reference system.

- Features and objects that contain attributes, temporal validity and position (geographical and/or linear).

- Object type libraries (data catalogue) with elements such as object types, value domains, and valid values.

- Metadata about information exchange (transactions) such as updates, permissions and subscriptions.

3.2.3 RAMM The Road Assessment and Maintenance Management software suite $\mathrm{RAMM}^{7}$ is used within road authorities in Australia, Fiji and New Zealand. The suite contains many different modules such as RAMM Manager, RAMM Network Manager and RAMM SQL to facilitate lookup, staff permissions, process and network maintenance, database manipulation and data extraction. Further modules are RAMM Contractor and Pocket RAMM for owners and contractors that require a better system for contract management. As well as the web-based modules Hosting Administration, RAMM GIS and Car Manager for permission management, map-based asset management and analysis, and managing corridor access requests, respectively (RAMM, 2016).

The software can also be used to manage assets that are not related to roads, such as buildings and open spaces. It provides the opportunity to view the assets and jobs on a map. One of the featured RAMM characteristics is a robust asset database with the support to perform assessments, asset valuations, forward work programmes and inspections.

3.2.4 Safe Software FME The Feature Manipulation Engine (FME) by Safe Software ${ }^{8}$ is a multifunctional tool for data handling. It provides the opportunity to transfer information between about 400 data sources without any coding requirements. The integrated FME transformer library helps to save time during tasks related to data restructuring and preparation. The FME can further automate workflows that turn unstructured data into scheduled, real-time, or self-serve processes. Some of the FME methods are described next:

- Asset management and planning: Keep the distribution network information current by translating external data from different data sources, delivering information effortless without data silos and preserving automated data integrity.

- Distribution network maintenance and operations: Deliver high-quality network information precisely by sharing workflows in a needed format, receiving data updates by using automated workflow translations, and experience time savings by setting up automated run intervals for configured workflows.

- Outage and leak management: Equip responders, customer service agents and clients, fast and efficient with their required information by automating the information distribution of incoming information immediately to the right person (e.g. decision maker or customer) in the right format.

\footnotetext{
${ }^{6}$ RailTopoModel: http://www.railtopomodel.org

${ }^{7}$ RAMM: http://www.ramm.com

${ }^{8}$ Safe Software: http://www.safe.com
}

- Preserve data quality and save time: Making data integration and data delivery seamless by supporting hundreds of data formats, re-using and automating workflows without the requirement to write source code while preserving the quality of critical data sets with no information lost while transferring data into another data format.

\section{IMPLEMENTATIONS}

Based on the overview provided previously, this section provides implementations by other working groups to indicate current developments in the area of road network information exchange.

\subsection{Verification IFC Alignment and InfraGML}

The IFC Alignment provides the opportunity to design a road, bridge or tunnel, and is integrated with import/export functionality in software solutions such as AutoCAD Civil 3D. Amann and Borrmann (2015) analysed the IFC Alignment and indicated the following disadvantages. It lacks to describe road cross sections, tunnel and bridge buildings. An IFC Alignment element is further always gap-free and, therefore, a new element must be created to describe a gap.

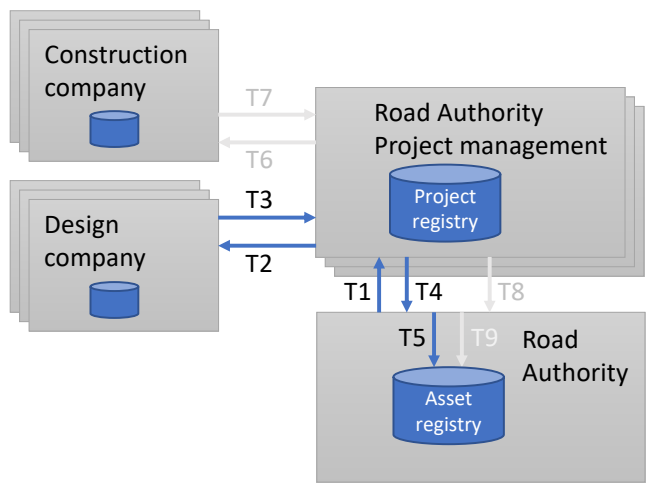

Figure 5. The information exchange (transactions) for the use case from the asset management to design, then to construction and back to asset management (Malmkvist et al., 2017).

Malmkvist et al. (2017) demonstrated that it is possible to exchange information between different software systems with the use of IFC Alignment and InfraGML. They managed to validate the scenario from asset management to design, then to construction and back to asset management. An illustration of the scenario is indicated in Figure 5, whereby:

T1 Transfer existing data from the infrastructure owner to the project management.

Utilised: IFC Alignment, INSPIRE, Novapoint, OpenTNF, OGC Geopackage, and TNE.

T2 The project management transfers data to the designer. Utilised: IFC, and Novapoint.

T3 The designer processed design and transfer the results (construction documentation) to the project management. Utilised: IFC Alignment, and Novapoint.

T4 Selected parts are transferred from the construction documentation by the project management to the infrastructure owner (road authority).

Utilised: ANDA, IFC, Novapoint, OpenTNF, and TNE. 
T5 Integrate the construction documentation into the asset registry and publish to the stakeholders.

Utilised: FME (custom workspace supplied by Safe Software to support InfraGML), InfraGML, Novapoint, PDF, and Shape formats.

(T6) Existing data and construction documentation is transferred by the project management to the construction company. which is carrying out the project consisting of the ...:

(a) Machine Control

(b) Detour

(c) Reporting

(T7) The construction company transfers as-built documentation to the project management.

(T8) Asset management data (part of as-built documentation) are transferred by the project management to the road authority.

(T9) Asset management data is integrated into asset registry and published to stakeholders.

The transactions T6 - T9 (light-grey transactions in Figure 5) has been excluded by Malmkvist et al. (2017) from the test due to the lack of system capability to handle the standards of interest. Any of their test systems supported transactions that included the road project management.

Malmkvist et al. (2017) faced the following hurdles within InfraGML and IFC Alignment while developing a solution for the transactions T1 - T5.

4.1.1 Hurdles with InfraGML During the development, they studied the InfraGML examples and discovered errors within these examples (e.g. use of radius value and not $1 / \mathrm{r}$ for the curvature, mixed use of the unit name "meter" and " $m$ ", and used "d" which means day to abbreviate a start angle instead of "deg" for degrees). Another issue related to the standard specification occurred while exchanging a transition curve between Novapoint and FME with the interpretation of the spiral starting point. They first believed that the spiral starting point is the coordinate at the beginning of the transition curve segment. After further investigation they interpreted it as "geographical coordinates that are congruent with the origin in the construction space for the Cornu's spiral" (Malmkvist et al., 2017, p.23).

4.1.2 Hurdles with IFC Alignment Outdated IFC documentations are not marked as obsolete and therefore misleading, such as for IFC Alignment 1.0 that can be found with the Google search engine. During the development, Malmkvist et al. (2017) studied the IFC Alignment examples and discovered issues within the use of these examples. For instance, the IFC documentation specifies that within the "horizontal alignment" example the parameter "name" for the coordinate reference system must be taken from the European Petroleum Survey Group (EPSG), however, they believe that the value of the data field "code" must be used instead. Another issue within the horizontal alignment example exists with the data field "geodetic datum" which has the value "EPSG:31467", the correct value for the geodetic datum is "EPSG:6314" (Deutsches Hauptdreiecksnetz) which can be identified using the EPSG $^{9}$ website. Malmkvist et al. (2017) also discovered issues within the IFC specification. For instance, the specification of the transition curve (IFC identifier "IfcTransitionCurveType") does not provide examples or algorithms that could be implemented within an acceptable time frame. An IFC

\footnotetext{
${ }^{9}$ EPSG Geodetic Parameter Registry: http://www.epsg-registry.org
}

Alignment example from other working groups contained a reserve transition curve segment, and it was not clear that this is supported in IFC Alignment 1.1, as the entity definition "IfcTransitionCurveSegment2D" does not mention the reserve transition. One more issue arose for the vertical curve and the asymmetric parabola. Although most applications handle this as one segment, IFC requires two individual segments. Curve segments (clothoids) with different curvature at the start and end are not supported by InfraGML, resulting in a negative influence on the compatibility between the alignment of IFC and InfraGML.

\subsection{Integration of BIM and GIS}

Schaller et al. (2017) describes a model to integrate BIM data into a GIS data format using a real-world data set of the German autobahn A99 expansion in Munich. Although they do not explained in detail the difficulties while implementing their solution, their approach proofed that BIM data can be transferred into a GIS data format. Their concept is shown in Figure 6, whereby the bidirectional transition between BIM and GIS data was performed from Schaller et al. (2017) by utilising Esri's interoperability extension, that uses an ETL (Extract-Transform-Load) based approach within FME. This data was then used by project designers and landscape planners. The feedback of the results was employed to improve the system. This allowed them to compare and to evaluate different CAD or BIM design and planning scenarios based on existing GIS data sets.

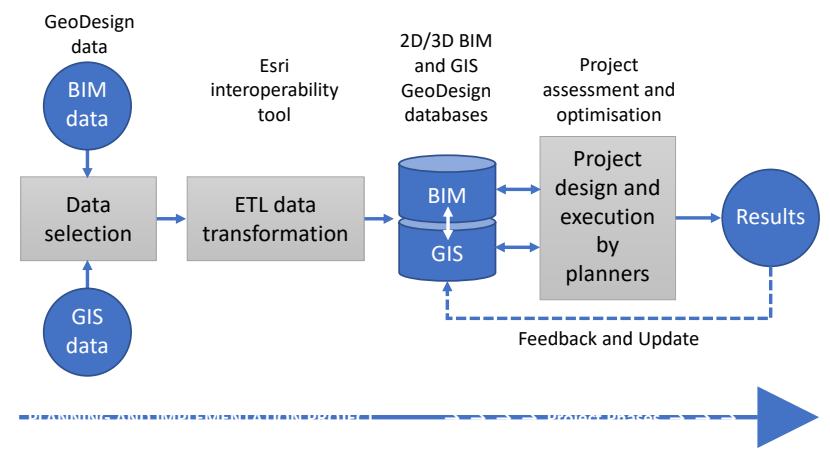

Figure 6. Concept employed by Schaller et al. (2017) for BIM/GIS data exchange.

Their used GIS software systems are Esri's ArcMap/ArcGIS Pro with the data interoperability extension for 2D/3D GIS data processing, analysis and visualisation. Esri CityEngine was employed for the development of procedural modelling scripts and export of required CGA packages into ArcGIS Pro. The infrastructure planners of the A99 expansion used to modelling and planning the following BIM/CAD software solutions: Autodesk Revit, Autodesk AutoCAD, Solibri Model Checker, Linear Project TILOS, and RIB iTWO.

A sample bridge structure converted from Revit into an IFC format, then processed through the data interoperability extension, and finally migrated into a GIS format is illustrated in Figure 7. The data was further then used for environmental analyses, such as building (site) impact analysis to identify the environmental impacts and compensation measures, and spatial analysis to determine permanent land consumption by the building and temporal land consumption by the construction site. 


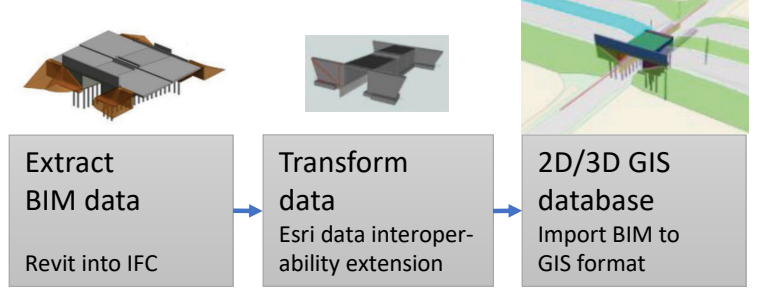

Figure 7. Example of a bridge structure migrated from BIM into GIS data (Schaller et al., 2017).

\section{CONCLUSIONS}

This paper provided an overview of standards for road asset management and evaluated these techniques for industrial application to the road network.

\begin{tabular}{|l|c|c|c|}
\hline Standard / Software & Novapoint & TNE & FME \\
\hline IFC & $\checkmark$ & $\checkmark^{*}$ & $\checkmark$ \\
\hline OpenTNF & $\checkmark$ & $\checkmark$ & - \\
\hline LandInfra/ InfraGML & $\checkmark$ & $\checkmark$ & $\checkmark^{* *}$ \\
\hline IFC Engine DLL & $\checkmark$ & - & - \\
\hline Austroads data standard & - & - & - \\
\hline IFC Alignment & $\checkmark$ & $\checkmark^{*}$ & $\checkmark^{*}$ \\
\hline OGC GeoPackage & - & $\checkmark$ & $\checkmark$ \\
\hline INSPIRE GML & $\checkmark$ (import) & $\checkmark$ & $\checkmark$ \\
\hline CityGML & $\checkmark$ & - & $\checkmark$ \\
\hline LandXML & $\checkmark$ & - & $\checkmark$ \\
\hline $\begin{array}{l}\text { *Currently under development } \\
\text { * Currenlty not publicly available }\end{array}$ \\
\hline
\end{tabular}

Table 1. Comparison of the software Trimble Novapoint, Triona TNE and Safe Software FME with applicable data standards for road asset information exchange.

The software solutions presented in this paper are compared to common data standards in Table 1, whereby the RAMM software in Section 3.2.3 has not been taken into account because no information related to data standard support are available. As visible in Table 1, the data standards IFC, IFC Alignment and LandInfra/InfraGML are well distributed within industrial available software solutions. The data standard INSPIRE GML is also well supported, however, Novapoint provides currently only an import functionality. None of these software systems enables the export into the Austroads data standard.

After comparing these standards, it can be said that if a stakeholder aims for road asset information exchange, then the use of the IFC, IFC Alignment and InfraGML developments should be considered, as these standards are well supported by industrial software applications. For the specific use in Australia and New Zealand, the Austroads data standard is intended to provide the basis for the information exchange between national transport agencies. However, the Austroads standard is still in the early development stage and no published proof of concept or examples available at the time of writing.

The industrial applications presented in this paper show an approach to share road asset data between different development stages and standards. The first example (see Section 4.1) indicates the information exchange transferring data from the design phase to the operational project management. The second example (see Section 4.2) shows the data exchange between BIM and GIS applications. Within these two projects many different standards are used (e.g. IFC, InfraGML and INSPIRE). It can be concluded that there is no single data standard available that handles all needs of a road project. In the future, probably more standards will exist, and the current developments will be improved. Therefore, instead of trying to develop more data standards for road asset information exchange an investigation can be done into translation approaches to let these standards seamlessly communicate with each other.

\section{ACKNOWLEDGEMENTS}

This work is supported financially by Australian Research Council project LP160100524, Curtin University, Australia's Sustainable Built Environment National Research Centre (SBEnrc) Project 2.33 and its partners. Core partners are Swinburne University of Technology, Queensland University of Technology, University of Melbourne, New Zealand Transport Agency, MRWA, Roads and Maritime Services and Aurecon Australasia PTY LTD.

\section{REFERENCES}

Amann, J. and Borrmann, A., 2015. Creating a 3D-BIMcompliant road design based on IFC alignment originating from an OKSTRA-accordant 2D road design using the TUM Open Infra Platform and the OKSTRA class library. Technische Universität München pp. 1-15.

Austroads, 2015. Austroads Annual Report 2014-15. Technical Report AP-C20-15, Austroads.

Austroads, 2016a. Austroads Annual Report 2015-16. Technical Report AP-C20-16, Austroads.

Austroads, 2016b. Data Standard for Road Management and Investment in Australia and New Zealand: Draft 1 Version 2.

Bø, D. B., 2015. Application of the ISO 55000 Suite for a LandBased Manufacturing Organization. Master's thesis, University of Stavanger, University of Stavanger. Faculty of Science and Technology.

BuildingSMART, 2017. Industry Foundation Classes. Version 4.1 Final Release.

Consultants, O. I., 2018. Data Standard for Road Management and Investment in Australia and New Zealand Version 2. Consultants, Opus International.

East, B., Kenley, R. and Harfield, T., 2016a. CONie: Lessons to be Learned from COBie Specifications and Standards. Technical report, Sustainable Built Environment National Research Centre (SBEnrc).

East, B., Kenley, R. and Harfield, T., 2016b. Network Asset Management Intervention: Designing CONie (Construction to Operations for Networks information exchange) for Australian and New Zealand Roads. Technical report, Sustainable Built Environment National Research Centre (SBEnrc).

Gelder, J., 2018. Asset Data Harmonisation Stage III: BIM IFC Alignment Review. Technical report, Austroads.

Haider, A., Koronios, A. and Kumar, A., 2012. An object oriented road asset information model. In: Engineering Asset Management and Infrastructure Sustainability, Springer, pp. 283-297.

Hausknecht, K., 2018. Wissenschaftliche Begleitung der BMVI Pilotprojekte zur Anwendung von BIM im Infrastrukturbau Endbericht Handlungsempfehlungen. pp. 1-30. 
INSPIRE, 2014. INSPIRE Infrastructure for Spatial Information in Europe D2.8.I.7Data Specification on Transport Networks - Technical Guidelines. Technical report, INSPIRE Thematic Working Group Transport Networks.

Kenley, R. and Harfield, T., 2015. New Project Management Models: Productivity Improvement for Infrastructure. Sustainable Built Environment National Research Centre (SBEnrc).

Kenley, R. and Seppänen, O., 2009. Location-Based Management for Construction: Planning, scheduling and control. Planning, scheduling and control, Spon Press.

Liebich, T., 2015. Proposal for IFC Alignment Extension. Technical report, BuildingSMART.

Malmkvist, M., Axelsson, P., Wikstrom, L., Bergman, O., Nilsson, A., Granberg, S., Jensen, J., Haggstrom, E., Sigfrid, J. and Karlsson, K., 2017. Alignment Deployment. Implementation report. Verification IFC Alignment \& InfraGML. Nordic project team. Technical report, BuildingSMART.

Maryland, 2014. State of Maryland. MD iMAP. One Maryland One Centerline (OMOC) Linear Referencing, http://imap.maryland.gov/Pages/road-centerlines-linearreferencing.aspx (27 July 2017).

McCrae, J. and Singh, K., 2009. Sketching Piecewise Clothoid Curves. Computers \& Graphics 33(4), pp. 452-461.

McPhee, A., 2016. Practical BIM. COBie is not what you think it is, http://practicalbim.blogspot.com.au/2016/03/cobie-isnot-what-you-think-it-is.html (31 March 2016).

Muhic, S., 2016. Linear Referencing. Technical report, BuildingSMART.

NCHRP, 1974. Highway Location Reference Methods. Synthesis of Highway Practice 21.

OGC, 2017. OGC InfraGML 1.0: Part 4 - LandInfra Roads Encoding Standard. Open Geospatial Consortium.

OpenTNF, 2017. White Paper Version 1.0 An open and efficient solution for exchange of Transport Network data.

Pecharda, C., 2017. D4. Principles for a European Road OTL. pp. 1-76.

RAMM, 2016. RAMM. Excellence in asset management. Working with RAMM, http://www.ramm.com/manuals/ WorkingwithRAMM/index.htm\#4438.htm (10 August 2016).

Scarponcini, P., 2002. Generalized Model for Linear Referencing in Transportation. GeoInformatica 6, pp. 33-55.

Schaller, J., Gnädinger, J., Reith, L., Freller, S. and Mattos, C., 2017. GeoDesign: Concept for Integration of BIM and GIS in Landscape Planning. Journal of Digital Landscape Architecture 2017, pp. 102.

Triona, 2018. Triona. Successful OpenTNF seminar, http:// www.triona.eu/news/2018/successful-opentnf-seminar/ (16 May 2018).

V-Con, 2016. V-Con Technical specification Phase 3. pp. 1-66. 